\title{
ECO-ROUTING: MORE GREEN DRIVERS MEANS MORE BENEFITS?
}

\author{
Cristina Valdés Serrano \\ Senior researcher, TRANSyT-UPM, Spain \\ Fiamma Perez Prada \\ PhD candidate, TRANSyT-UPM, Spain \\ Andrés Monzón de Cáceres
}

Professor, Transport Department, Universidad Politecnica de Madrid, Spain.

\begin{abstract}
Information and Communications Technology (ICT)/Information and Technology Services (ITS) can play an important role in the transport sector, helping in maintaining accessibility and contemporarily optimizing the use of the vehicles. Among these ICT measures, ecorouting seems a promising one. Drivers normally follow the route which minimizes their generalized costs, normally time and money. But environmental concern is increasing, and drivers are starting to think about the effects of their driving. This means including $\mathrm{CO} 2$ emissions or fuel consumption in their route choice. But is this always positive, independently of the traffic situation and the penetration level of green drivers?

This articles aims to analyze what happens in terms of fuel consumption, $\mathrm{CO} 2$ emissions and travel time, when different penetration levels of drivers, and with different traffic situations, follow the route of minimum fuel consumption instead of the conventional generalized costs. The analysis is based on a modelling process using a transport model of the whole region of Madrid. A total of 18 scenarios are considered: 3 reference scenarios (for congested, medium and low flow traffic situations), and 5 different penetration levels of green drivers for each traffic situation.
\end{abstract}

Results show how impact varies substantially with the level of traffic and, also, that the more the best is not always true.

\section{INTRODUCTION AND OBJECTIVES}

Road transport is the mode consuming most energy in the EU-27 (Eurostat, 2009). From 1990 to 2006, the final energy consumption of road transport grew at an annual rate of 1.6 $\%$, to reach 303.3 million toe in 2006 , which amounted to $25.8 \%$ of total final energy consumption, and to $81.9 \%$ of consumption in transport, compared to a share of $83.7 \%$ in 1990. Over the shorter 1995-to-2006 period, final energy consumption in road transport grew by $1.8 \%$ yearly which, over that period, compares to an annual increase in the performance of road passenger transport (passenger cars, powered two-wheelers, buses and coaches) of $1.5 \%$ and an increase in road freight transport of $3.5 \%$.

Thus, total GHG emissions of 992.3 million tonnes $\mathrm{CO} 2$ equivalent were attributable to 
transport in the EU-27 in 2006. Second largest after the energy industries (31\%), transport made up a share of $19 \%$ of total GHG emissions.

In comparison to an average yearly decrease in total GHG emissions of $0.5 \%$ in the EU-27 from 1990 to 2006, transport was the only sector not to display a reduction in emissions, rather recording growth at an average annual rate of $1.5 \%$ over the period. A major part of the increase was attributable to road transport which represents approximately $93 \%$ of total transport generated GHG emissions ( $18 \%$ of total GHG emissions in Europe).

At the same time, the EU has called for, and the international community agreed on, the need to drastically reduce world greenhouse gas (GHG) emissions, with the goal of limiting temperature change below $2^{\circ} \mathrm{C}$. Overall, the EU needs to reduce emissions by 80-95\% below 1990 levels by 2050, in the context of the necessary reductions of the developed countries as a group, in order to reach this goal (EC, 2011). The White Paper concludes that a transformation of the European transport system and, therefore, the necessary reductions of GHG emissions, will only be possible through a combination of manifold initiatives at all levels.

This combination involves bringing significant improvements to the European road transport system. The research and innovation proposed in the Strategic Research Agenda (SRA) of ERTRAC Technology Platform (ERTRAC, 2011) aims at enabling such improvements by addressing the broad range of challenges related to the road transport system, including: the supply of energy and resources; global climate change and the environment; health and safety; and increased global competitiveness of the road transport industry leading to economic growth and high quality employment in Europe. The approach taken by the SRA recognizes, in particular, the societal demand for decarbonization, reliability and safety of the road transport system from a user's perspective. For each of these societal needs, clear indicators have been selected, each with specific guiding objectives towards 2030. Combined, these indicators provide a plausible reference to the headline objective of a $50 \%$ more efficient road transport system.

In this framework, Information and Communications Technologies (ICTs) have been identified as having the potential to reduce the energy consumption and emissions of road vehicles, but significant results and quantitative data are still missing (ERTRAC, 2011; ECMETI Task Force, 2009).

So far, only a few Intelligent Transport Systems (ITS) - which are based on ICTs - have specifically addressed environmental aspects. The environmental effects of ITS strategies have generally been viewed as secondary to the effects on accidents, congestion and journey times. Tangible results are needed to support the wider deployment of 'Green ITS' services. In parallel there is an urgent need for more research in the area of optimal technological change and technological diffusion involving multi-discipilinary cooperation between engineers, social scientists and end users in order to detect the true potential and benefits of 
various forms of ICT driven innovations for a more energy efficient society. This will require extensive cross-disciplinary and cross-sectoral approach for an enhanced holistic view of ICTs.

Within this framework, the European project ICT-EMISSIONS (http://www.ictemissions.eu) aims at providing knowledge on the impact of ICT-related measures on mobility, vehicle energy consumption and $\mathrm{CO} 2$ emissions at the local scale, in order to promote the wider application of the most appropriate ICT measures. This article is focused on Green Navigation.

The methodology developed within the project, as well as the results of other ICT measures considered, can be found in García-Castro and Monzón (2014a), García-Castro and Monzón (2014b), Toffolo et al (2014), Toffolo et al (2013), Valdés et al (2015a), Valdés et al (2015b) and Samaras et al (2016).

\section{DATA AND METHODOLOGY}

\subsection{The transport model}

The tool used for macro scale simulations is an assignment model developed using the PTVVISUM software. The macro traffic model covers the whole region of Madrid - an area of 8,026 square $\mathrm{km}$ and home to 6 million inhabitants. The city of Madrid - with a population density of 5,208.6 inhabitants/square $\mathrm{km}$ - is located in the centre of the region (in orange in Fig.1). The rest of the region is formed by other 179 municipalities. The affection of the traffic from border regions is negligible compared with the internal traffic of the region.

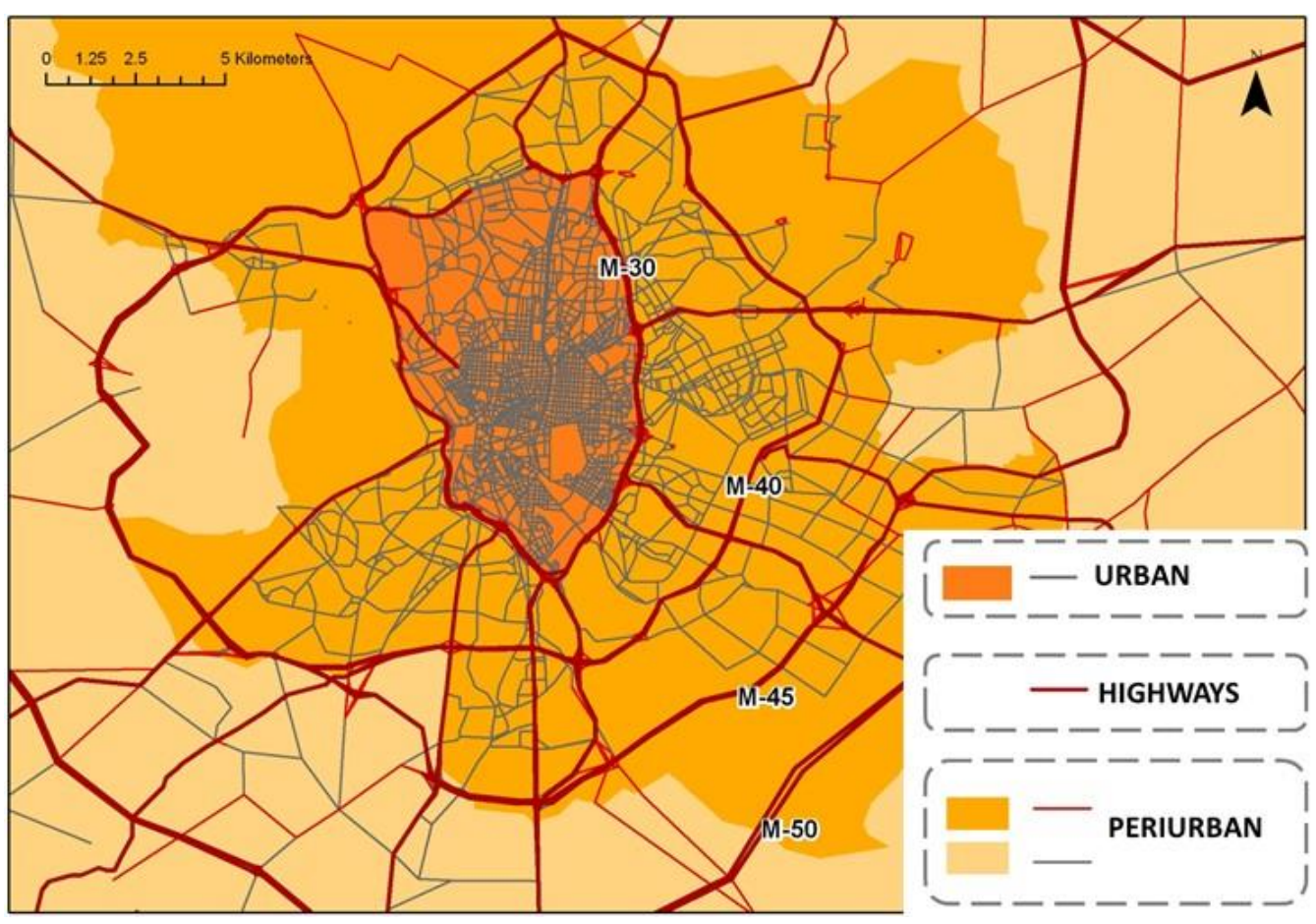

Fig.1 - Madrid's network structure 
The road network has a radio centric structure with eight main free radial highways linking central Madrid and all the Spain's coastal regions and four ring-roads (two of them unfinished) encircling it: the first one is the M-30, which divides the city into two parts, the inner part -Central Area - and the peripheral districts, and it functions as a local distributor road; the second is the M-40, which encompasses most of the city of Madrid, and is the most congested road in the Madrid metropolitan area; and the M-45 and M-50, both yet incomplete rings.

Running in parallel to four of the main highways, are four toll highways (R-2, R-3, R-4 and R-5), which end in the surrounding rings M-40 (R-2, R-3 and R-5) and M-50 (R-4).

The model has been developed for three different traffic situations: free flow, medium traffic and congestion. Time periods corresponding to medium (6-7 am, 9 am-2 pm, 3-6 pm and 8$10 \mathrm{pm}$ ) and congested situation (7-9 am) have been determined after a detailed traffic analysis of the city of Madrid, while free flow corresponds to either very early in the morning or close to midnight.

The O-D matrix obtained from the EDM 2004 was calibrated by using more than 270 traffic flow counters from the Ministry of Transport and Infrastructure (MFOM,2005), the Road Department of the Regional Government of Madrid (CM,2005) and the Mobility Department of the Madrid City Council (Ayuntamiento de Madrid,2005).

The fit obtained shows a good convergence between the real data of traffic flow and the results obtained from assigning the new morning rush hour matrix, with an R2 of 0.735 and 0.712 for respectively the congested situation and the medium traffic period.

\subsection{Methodological approach}

\section{Measure description}

Green navigation implies routing recommendations based on calculation of environmental impact and real-time traffic situation. This means, in practice, people following the route which minimizes their emissions.

\section{Modelling process}

For modelling green-navigation a new transport mode had to be defined in VISUM. This new transport mode, green-navigation drivers, has assigned a new impedance function defined in terms of fuel consumption (directly related to $\mathrm{CO} 2$ emissions) instead of the typical impedance function for conventional drivers which is based on time and monetary costs.

$I_{\text {green }}=F C\left(V_{\text {Cur }}\right) \cdot t_{\text {Cur }}$

From different studies, five different fuel consumption functions were tested. Figure 20 shows the fuel consumption function selected, the one which better performs at congested traffic conditions. 


$$
F C=-0.000000000329612 * V \text { Cur }^{5}+0.00000010979 * V \text { Cur }^{4}-0.0000118935 *
$$

$V_{C u r}^{3}+0.000530345 *$ VCur $^{2}-0.00156253 *$ Vcur +0.256344

A percentage of the light vehicles OD matrices will be assigned depending on the green navigation penetration rate i.e. if a penetration rate $25 \%$ of green drivers is considered, the $75 \%$ of the OD matrix will be assigned for conventional drivers under the typical impedance function and the rest $25 \%$ to green drivers under a impedance function based on fuel consumption.

Green drivers will select their preferable route depending on the actual traffic conditions, therefore and to capture this effect accurately, the assignment process is divided in two steps or assignment groups. First heavy vehicles and conventional car drivers are assigned to the network and subsequently the impedance function of green drivers is calculated for the new traffic levels and average speeds. By the second assignment group, green drivers are assigned to the network but instead of doing it in a single step, the process is divided in ten stages in order to continuously capture the new traffic conditions. Therefore, a $10 \%$ of the OD matrix corresponding to green drivers is assigned in each sub-step and the impedance function is recalculated after every assignment.

\section{Scenarios}

A total of 18 scenarios have been considered, three basecases and 15 with green drivers. Variables producing this wide range of scenarios are:

- Traffic level: free flow, medium flow or congested flow

- Penetration levels of green drivers: 10 - 25 - 50 - 75 and $90 \%$

\section{RESULTS AND DISCUSSION}

In global terms we can see that results either in terms of traffic and $\mathrm{CO} 2$ emissions vary substantially according to the traffic level (Table 1), having a positive impact for low and high traffic situations but not for medium flow. These benefits increase more with lower penetration levels, while with penetration levels over $75 \%$ it seems be close to an asymptote.

\begin{tabular}{|c|c|c|c|c|c|}
\hline \multirow{2}{*}{$\begin{array}{c}\text { Scenario } \\
\text { description }\end{array}$} & \multicolumn{5}{|c|}{ Variation respect to the basecase } \\
\hline & $\begin{array}{c}\text { CO2 abs } \\
\text { kg }\end{array}$ & $\begin{array}{l}\text { CO2 rel } \\
\mathrm{g} / \mathrm{km}\end{array}$ & veh·km & veh.h & $\begin{array}{c}\text { average } \\
\text { speed } k m / h\end{array}$ \\
\hline BASE_Congested & $1,080,693$ & 183 & $5,884,833$ & 98,324 & 59.8 \\
\hline Congested_10\% & $-2.22 \%$ & $1.48 \%$ & $-3.65 \%$ & $6.65 \%$ & $-9.66 \%$ \\
\hline Congested_25\% & $-4.89 \%$ & $3.09 \%$ & $-7.74 \%$ & $13.96 \%$ & $-19.04 \%$ \\
\hline Congested_50\% & $-7.07 \%$ & $4.78 \%$ & $-11.31 \%$ & $21.21 \%$ & $-26.83 \%$ \\
\hline Congested_75\% & $-7.92 \%$ & $5.78 \%$ & $-12.95 \%$ & $25.60 \%$ & $-30.69 \%$ \\
\hline Congested_90\% & $-8.16 \%$ & $6.19 \%$ & $-13.51 \%$ & $28.72 \%$ & $-32.81 \%$ \\
\hline
\end{tabular}




\begin{tabular}{|c|c|c|c|c|c|}
\hline \multirow{2}{*}{$\begin{array}{c}\text { Scenario } \\
\text { description }\end{array}$} & \multicolumn{5}{|c|}{ Variation respect to the basecase } \\
\hline & $\begin{array}{c}\text { CO2 abs } \\
\text { kg }\end{array}$ & $\begin{array}{l}\text { CO2 rel } \\
\text { g/km }\end{array}$ & veh·km & veh·h & $\begin{array}{c}\text { average } \\
\text { speed } k m / h\end{array}$ \\
\hline BASE_Medium & 794,732 & 180 & $4,405,331$ & 60,698 & 73 \\
\hline Medium_10\% & $-1.13 \%$ & $0.49 \%$ & $-1.61 \%$ & $5.65 \%$ & $-6.87 \%$ \\
\hline Medium_25\% & $-2.24 \%$ & $1.58 \%$ & $-3.76 \%$ & $12.05 \%$ & $-14.12 \%$ \\
\hline Medium_50\% & $-3.18 \%$ & $2.94 \%$ & $-5.94 \%$ & $20.53 \%$ & $-21.97 \%$ \\
\hline Medium_75\% & $-4.08 \%$ & $3.79 \%$ & $-7.58 \%$ & $27.32 \%$ & $-27.41 \%$ \\
\hline Medium_90\% & $-4.66 \%$ & $4.23 \%$ & $-8.53 \%$ & $31.67 \%$ & $-30.53 \%$ \\
\hline BASE_Free & 391,935 & 180 & $2,170,921$ & 26,096 & 82,9 \\
\hline Free_10\% & $-5.91 \%$ & $-0.07 \%$ & $-5.85 \%$ & $-3.62 \%$ & $-2.31 \%$ \\
\hline Free_25\% & $-6.83 \%$ & $-0.08 \%$ & $-6.76 \%$ & $0.20 \%$ & $-6.94 \%$ \\
\hline Free_50\% & $-7.85 \%$ & $0.00 \%$ & $-7.85 \%$ & $7.11 \%$ & $-13.97 \%$ \\
\hline Free_75\% & $-8.93 \%$ & $0.01 \%$ & $-8.94 \%$ & $13.11 \%$ & $-19.50 \%$ \\
\hline Free_90\% & $-9.47 \%$ & $0.02 \%$ & $-9.48 \%$ & $16.73 \%$ & $-22.46 \%$ \\
\hline
\end{tabular}

Table 1 - Results: variation respect to the basecase

When disaggregating these results into road types (see Figure 2), we can observe that the benefit concentrates in motorways and highways while urban streets and extra urban roads. This means drivers following "the greener route" are selecting shorter routes, though this may imply crossing the city center or selecting a road with lower speed than a highway.
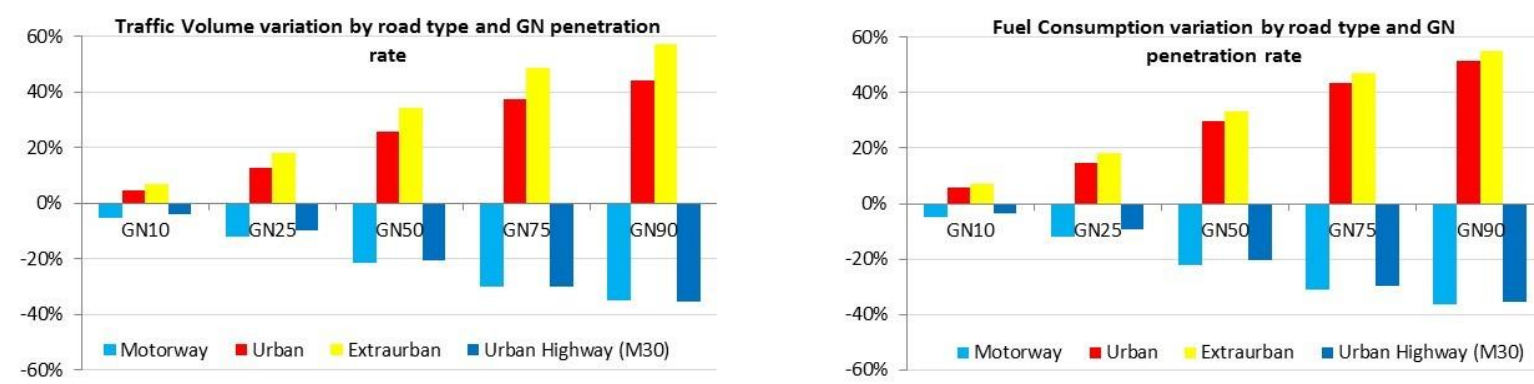

Fig.2 - Traffic volume and fuel consumption variation by road type and GN penetration level.

But this has a negative aspect, which is the time increase (Figure 3). As length has an important effect in $\mathrm{CO} 2$ emissions, green drivers choose routes similar to the minimum length, even having higher travel times. 


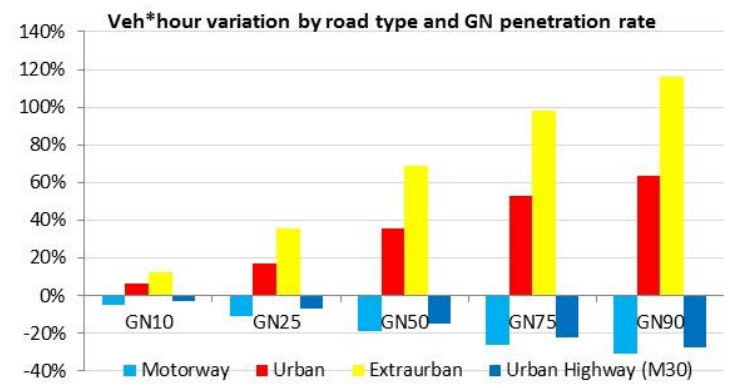

Fig.3 - Travel Time variation by road type and GN penetration level.

\section{CONCLUSIONS}

Green Navigation has a high potential in $\mathrm{CO} 2$ emissions decrease, though results evidence a travel time increase which is not very realistic. But this equilibrium between fuel consumption and travel time saving is a research gap to explore: each trip is conditioned by different time and monetary restrictions, as well as to a certain uncertainty. This implies, citizens being aware of their possible benefits - in terms of fuel consumption and therefore monetary costs -, the route selection may change for some trips, even given this time increase. The second finding of this measure is, as length has an important weight in minimizing fuel consumption, drivers follow shorter routes, which sometimes cross city centers, therefore producing an increase of veh-km in these areas and decreasing traffic of peripheral roads. In this case, though producing a global benefit in terms of $\mathrm{CO} 2$, it may produce an increase in local pollutants, which is also a main problems for city authorities. But, what happens if Green Navigation is combined with other ICT measures, i.e. Start and Stop?

\section{ACKNOWLEDGMENTS}

This work was supported partially by the European Commission under the ICT-Emissions project, "Development of a methodology and tools for assessing the impact of ICT measures in road transport emissions," Grant Agreement No. 288568. The authors also acknowledge the collaboration of the City of Madrid and Calle-30 in the process of data collection.

\section{REFERENCES}

Eurostat, 2009. Panorama of Transport 1990-2006. Author, Dominic Huggins. Eurostat, European Commission. Available at http://epp.eurostat.ec.europa.eu/cache/ITY_OFFPUB/KS-DA-09-001/EN/KS-DA-09-001EN.PDF

European Commission (EC), 2011. White Paper on transport. Available at http://ec.europa.eu/transport/themes/strategies/doc/2011_white_paper/white-paperillustrated-brochure_en.pdf 
European Road Transport ResearchAdvisory Council (ERTRAC) (2011) Research and Innovation Roadmaps. Implementation of the ERTRAC Strategic Research Agenda 2010. Available at http://www.ertrac.org/pictures/downloadmanager/6/50/ertracresearchinnovation-roadmaps_60.pdf

EC-METI Task Force (2009). Methodologies for assessing the impact of ITS applications on CO2 emissions. Spence A, Turksma S, Schelling A, Benz T, Medevielle J-P, McCrae I, Jaaskelainen J and Boethius E. Technical Report V1.0.

Garcia-Castro, A., Monzon, A., 2014a. Homogenization Effects of Variable Speed Limits. Transport and Telecommunication Journal 15.2, pp:130-143. ISSN 1407-6160. (http://www.degruyter.com/view/j/ttj.2014.15.issue-2/ttj-2014-0012/ttj-2014-0012.xml)

Garcia-Castro, A., Monzon, A., 2014b. Calibration of Traffic Simulators Using Floating Car Data. Sensors 2014, 14(11), 21358-21374; doi:10.3390/s141121358 (http://www.mdpi.com/1424-8220/14/11/21358)

Toffolo, S., Moreelo, E., Samaras, Z., Ntziachristos, L., Vock, C., Maier, W., Garcia-Castro, A., 2014. ICT-emissions methodology for assessing ITS and ICT solutions. Transport Research Arena Congress, 14 -17 April 2014, Paris.

Toffolo, S., Vock, C., Ntziachristos, L., Samaras, Z., Maier, W., Valdes, C., \& GarciaCastro, A. (2015). Manual of procedures for use of the methodology. (Deliverable No. D5.2). Brussels, Belgium: ICT-Emissions Consortium.

Valdes, C., Garcia-Castro, A., Perez-Prada, F., Tuffanelli, G., Cianfano, M., Magra, G., Toffollo, S., Monzon, A., 2015. Field trials and simulation comparison. ICT-Emissions project: Deliverable 6.2. European Comission (7th Framework Programme), pp. 69.

Valdes, C., Garcia-Castro, A., Perez-Prada, F., Tuffanelli, G., Cianfano, M., Magra, G., Toffollo, S., Vock, C., Werner, M., Monzon, A., 2015. Results of application of ICT measures in ICT-EMISSIONS partner cities. ICT-Emissions project: Deliverable 6.3. European Comission (7th Framework Programme), pp. 17-28. 